\title{
Análise da Secagem de Folhas e Hastes de Hortelã em Camada Fina
}

\author{
T. M. KONDO ${ }^{1}$, A. H. ROSANOVA ${ }^{2}$, M.C. FERREIRA ${ }^{1}$ \\ ${ }^{1}$ Universidade Federal de São Carlos, Departamento de Engenharia Química \\ ${ }^{2}$ Universidade Federal de São Carlos, PPG-EQ \\ E-mail para contato: tiemi.kondo@hotmail.com
}

\begin{abstract}
RESUMO - Este trabalho teve como objetivo analisar a cinética de secagem das folhas e hastes da hortelã-comum (Mentha x villosa Huds) em camada fina. Inicialmente, foi analisada a secagem das folhas, posteriormente das hastes e por fim, do conjunto formado por folhas e hastes, de forma combinada. Além de comparar as cinéticas de secagem dos diferentes materiais, foram avaliadas também a influência da temperatura e a influência da velocidade do ar no processo de secagem convectiva em camada-fina. A partir do ajuste dos dados experimentais à equação empírica de Lewis, foram estimados parâmetros cinéticos visando à estimativa das taxas de secagem para cada situação.
\end{abstract}

\section{INTRODUÇÃO}

A hortelã pertence à família Lamiaceae e ao gênero menthe, que apresenta uma vasta gama de espécies como a hortelã-verde (Mentha spicata), hortelã-crespa (Mentha crispa) e hortelãzinha (Mentha pulegium), além da hortelã-comum (Mentha x villosa Huds) (COSTA, 2013), a variedade mais encontrada no Brasil.

Por se tratar de um material biológico, a hortelã começa a se degradar irreversivelmente a partir do momento em que é colhida. Por isso, deve ser comercializada e consumida imediatamente, ou, para permitir a conservação por períodos de tempo maiores, deve ser desidratada o mais rapidamente possível, visando minimizar perdas dos princípios ativos. A secagem convectiva é um dos métodos mais utilizados para a preservação da hortelã, porque facilita o manuseio, transporte e armazenagem já que reduz o volume a ser processado, e permite o processamento e extração de óleos essenciais independentemente da sazonalidade.

A planta é composta por folhas e hastes, e essas duas partes apresentam características físicas, muito distintas. Quando comparadas com as hastes, as folhas possuem menor espessura, maior área superficial e menor umidade inicial (Rosanova et al., 2017). Essas diferenças podem impactar a homogeneidade da secagem de ramos de hortelã.

O objetivo deste estudo foi analisar a secagem convectiva em camada-fina de folhas, hastes e ramos, compostos pelos dois primeiros, visando comparar o comportamento de cada material e avaliar, por meio de equações empíricas, as taxas de secagem.

\section{METODOLOGIA}

Para este estudo a hortelã-comum, da espécie Mentha x villosa Huds, foi obtida no comércio local de São Carlos. As plantas foram selecionadas, lavadas com água corrente e secas com folhas de papel absorvente. As folhas foram separadas das hastes manualmente para os ensaios de secagem de folhas e hastes individualmente. As folhas foram utilizadas 
inteiras, as hastes picadas. Para a secagem do conjunto, utilizou-se os caules com as folhas, também picados em comprimentos adequados às dimensões da célula de medida.

\subsection{Equipamentos}

Nos ensaios foi utilizada uma linha de fornecimento de ar, ilustrada esquematicamente na Figura 1(a). O ar era fornecido por um soprador (1) de 7,5HP, e sua vazão era ajustada por duas válvulas do tipo gaveta e determinada pela leitura da diferença de pressão em um manômetro de água do tipo U, conectado a um medidor de vazão tipo dupla placa de orifício. $\mathrm{O}$ ar era aquecido por um aquecedor elétrico (5) de $2500 \mathrm{~W}$, ligado a um variador de voltagem (6), escoava por uma tubulação de $5,0 \mathrm{~cm}$ de diâmetro e ao final desta tubulação uma expansão cônica metálica foi adicionada, com o objetivo de aumentar o diâmetro da tubulação de 5,0 $\mathrm{cm}$ para $10,0 \mathrm{~cm}$. A fim de uniformizar o escoamento do ar que chegava a célula adicionou-se, após a expansão, um sistema distribuidor constituído por um leito fixo de esferas de vidro $\left(d_{p}=2,8 \mathrm{~cm}\right)$, com $3,0 \mathrm{~cm}$ de espessura, que ficava preso entre duas telas metálicas. A célula de secagem em camada fina foi acoplada a extremidade do duto (7). A célula de secagem (Figura 2) possuía uma tela metálica em cada uma de suas extremidades e um orifício para inserção do termopar em sua base, com o qual era feita a leitura da temperatura do ar na entrada da célula. As dimensões da célula estão indicadas na Figura 2. Foi adotada espessura de $1 \mathrm{~cm}$ com base em recomendação de Lima (2013), que verificou experimentalmente a condição de camada-fina para secagem de folhas em condições similares às usadas no presente estudo.

Figura 1- (a) Linha de fornecimento de ar; (b) célula de medida
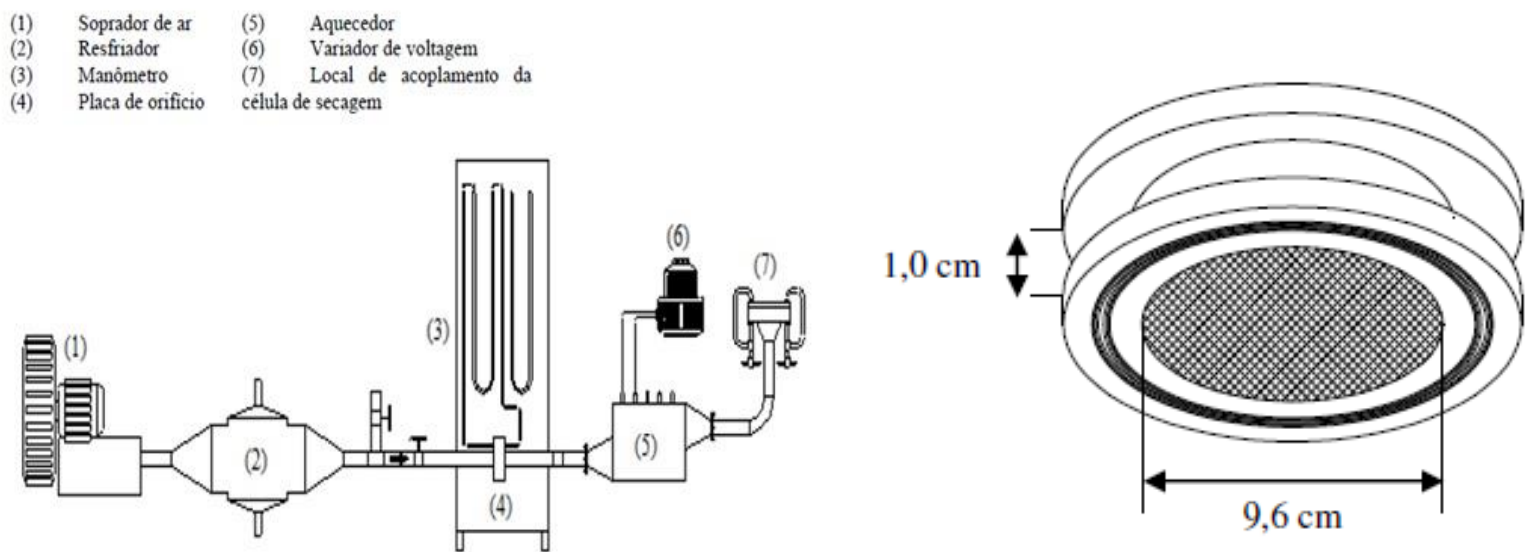

Fonte: Adaptado de Lima, 2013.

\subsection{Procedimento Experimental}

Os ensaios foram feitos inicialmente apenas com leitos constituídos pelas folhas da planta, posteriormente por leitos constituídos apenas pelas hastes e por fim leitos formados pelas hastes juntamente com as folhas. Uma massa de $8 \mathrm{~g}$ de material era inserida na célula de secagem em pequenas quantidades, e após cada adição eram realizadas batidas na célula, a fim de acomodar as folhas, hastes ou ramos, com composição mássica média de cerca de $70 \%$ folhas e $30 \%$ hastes. As temperaturas de 50 e $60^{\circ} \mathrm{C}$ foram escolhidas por serem utilizadas usualmente na secagem de plantas, assim como as velocidades de escoamento 1,0 e 1,5 m/s (COSTA, 2013; LIMA, 2012; PARK, 2002). 
A alimentação de ar era iniciada e a temperatura e velocidade de escoamento do ar ajustadas. Esperava-se que o sistema atingisse uma condição de estabilidade, com temperatura constante, apenas depois disso a célula de secagem era acoplada à unidade experimental. Em intervalos de tempos a célula de secagem era retirada da unidade experimental e pesada em uma balança analítica da marca GEHAKA modelo BG400 com precisão de 0,001g, até que a variação entre 2 medidas consecutivas fosse menor do que $0,010 \mathrm{~g}$, indicando que a umidade de equilíbrio dinâmico foi atingida. Para uma avaliação da reprodutibilidade dos ensaios foram realizadas três repetições para cada condição de operação. Com os dados construiu-se curvas de umidade adimensional em função do tempo. A umidade adimensional é definida pela equação:

$M R=\frac{U-U_{e}}{U_{i}-U_{e}}$

onde $U$ é umidade em um dado tempo, $U_{e}$ é umidade de equilíbrio dinâmico e $U_{i}$ é a umidade inicial.

Os dados experimentais foram ajustados à equação do modelo empírico de Lewis:

$\mathrm{MR}=\exp (-\mathrm{kt})$

onde t é o tempo e k é o parâmetro de ajuste, denominado constante de secagem.

\section{DISCUSSÃO E RESULTADOS}

Nesta seção serão apresentados e discutidos os dados obtidos neste trabalho.

Na Figura 2 é possível observar a influência da temperatura na secagem de folhas e hastes de hortelã para velocidade $1,5 \mathrm{~m} / \mathrm{s}$.

Figura 2 - Umidade adimensional em função do tempo na secagem de hortelã para velocidade do ar de 1,5 m/s, (a) hastes; (b) folhas.
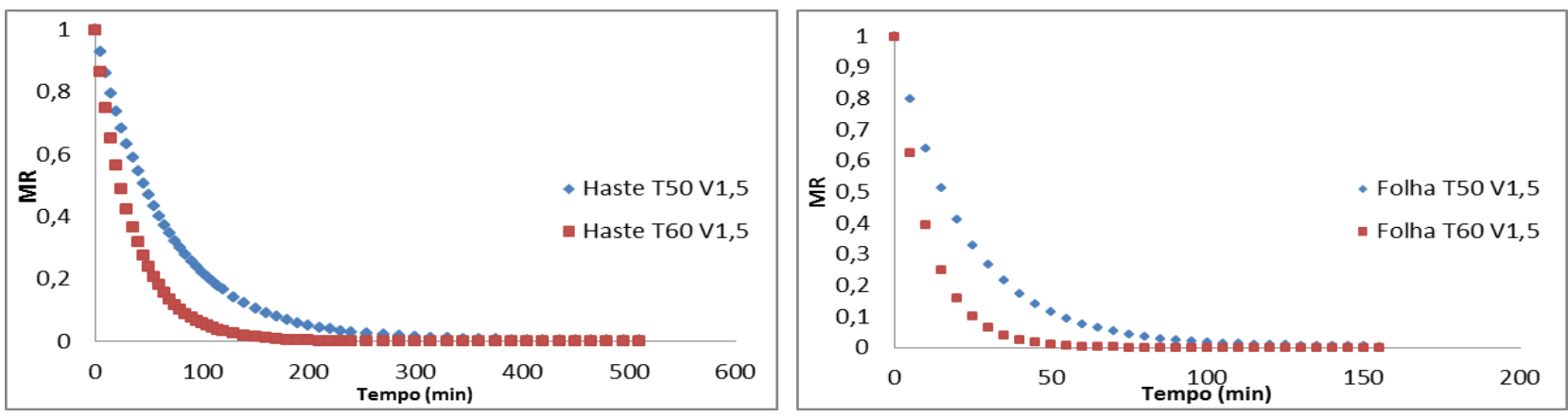

Fonte: Acervo pessoal, 2016.

Pode-se observar que a temperatura tem grande influência na taxa de secagem tanto das folhas como das hastes, pois com o aumento da temperatura observa-se um aumento significativo na taxa de secagem e, consequentemente, uma diminuição no tempo necessário para alcançar a umidade de equilíbrio. Analisando o gráfico das hastes, por exemplo, percebe- 


\section{Congresso Brasileiro de Engenharia Química \\ em Iniciação Científica \\ UFSCar - São Carlos - SP \\ 16 a 19 de Julho de 2017}

CONGRESSO BRASILEIRO DE ENGENHARIA

se que a $60^{\circ} \mathrm{C}$ a secagem atinge o equilíbrio no tempo de 350 minutos aproximadamente, enquanto que para $50^{\circ} \mathrm{C}$ esse tempo ultrapassa os 500 minutos, o que evidencia que a taxa de secagem é maior a $60^{\circ} \mathrm{C}$. Além disso, analisando os dados observa-se que a secagem ocorre, predominantemente, no período de taxa decrescente. Isso indica que o transporte interno de umidade, comandado por efeitos difusivos, é o mecanismo limitante no processo.

A velocidade apresenta uma influência muito pequena quando comparada com a influência da temperatura. Na figura 3, pode-se notar que o aumento da velocidade proporcionou variações pequenas na velocidade de secagem. Nos dois casos (hastes e folhas) a taxa de secagem foi ligeiramente maior para a velocidade de $1,5 \mathrm{~m} / \mathrm{s}$, o que é explicado pelo fato de que a uma temperatura fixa, o aumento de vazão implica no aumento da quantidade de energia fornecida ao processo, e consequentemente uma taxa de secagem mais elevada.

Figura 3 - Umidade adimensional em função do tempo na secagem de hortelã para temperatura do ar de $50^{\circ} \mathrm{C}$, (a) hastes; (b) folhas.

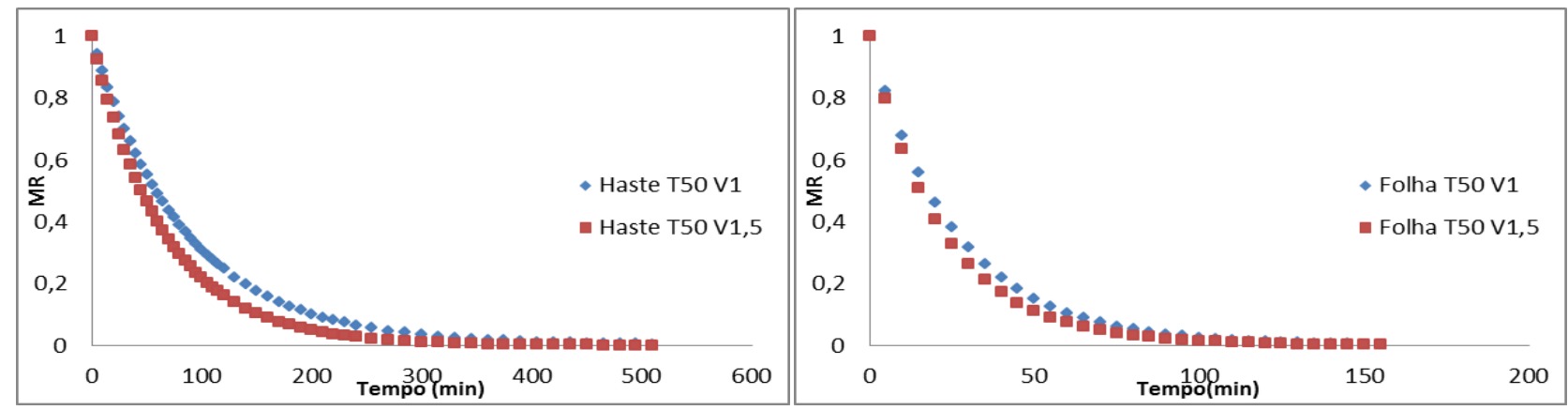

Fonte: Acervo pessoal, 2016

Nas curvas apresentadas na Figura 5 podem ser comparadas as cinéticas de secagem das folhas, hastes e ramos de hortelã. Analisando essas curvas nota-se que as folhas apresentam maiores taxas de secagem, os ramos taxas intermediárias e as hastes apresentam as menores taxas.

Figura 4 - Comparação gráfica dos tipos de materiais para cada condição de secagem
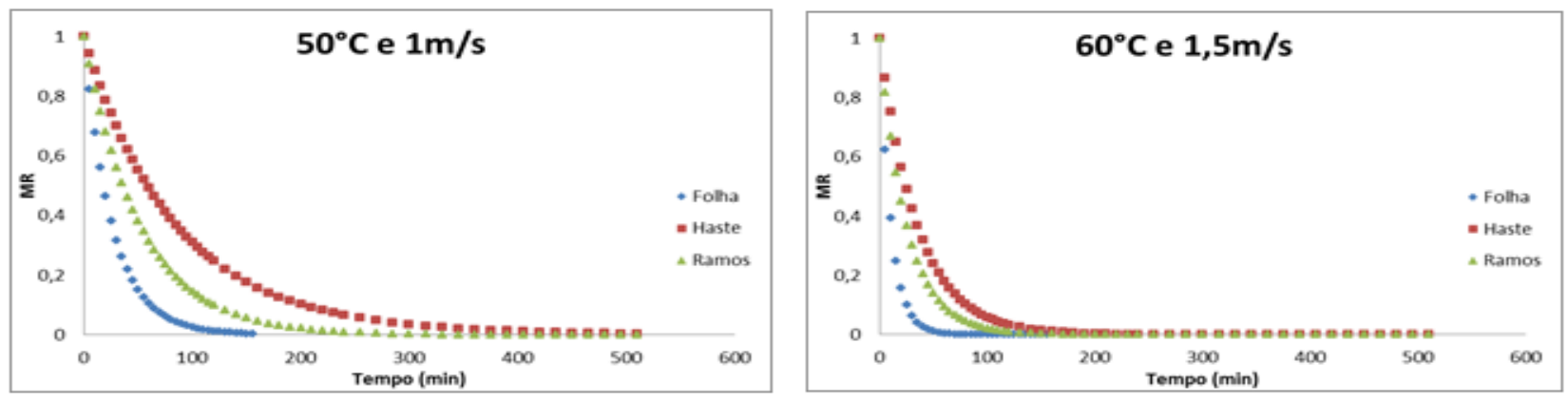

Fonte: Acervo pessoal, 2016.

As diferenças nas taxas de secagem das folhas e hastes são explicadas pelas características dos materiais. Segundo Rosanova et al. (2017), o diâmetro das hastes da hortelã comum é em média $2,5 \pm 0,5 \mathrm{~mm}$ e sua umidade inicial é $10 \pm 3 \mathrm{~g}_{\mathrm{H} 2 \mathrm{O}} / \mathrm{g}_{\mathrm{ss}}$, As folhas possuem espessura média de $0,18 \pm 0,02$ e umidade de $6 \pm 1 \mathrm{~g}_{\mathrm{H} 2 \mathrm{O}} / \mathrm{g}_{\mathrm{ss}}$ e sua área superficial é cerca de 15 vezes maior que a área superficial das hastes. Assumindo que as difusividades efetivas sejam da mesma ordem de grandeza, comparativamente, as folhas oferecem menor resistência ao transporte de umidade devido a menor dimensão característica. Nota-se que as 
estruturas físicas dos materiais também são diferentes, o que possivelmente contribui para as diferenças nas taxas de transporte de umidade. Os ramos se comportaram como o esperado, pois são constituídos de folhas e hastes e apresentaram uma taxa intermediária entre os dois materiais isolados.

Foi observado que no decorrer da secagem a hortelã sofria um encolhimento acentuado. Com isso, os leitos dos materiais não eram homogêneos, pois havia a formação de espaços vazios e canais preferenciais de passagem do ar, como pode ser visualizado nas fotos da Figura 5.

Figura 5 - Imagem da secagem de ramos em tempos de secagem distintos.

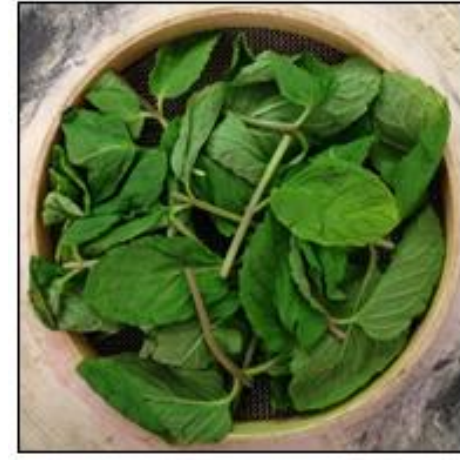

$\mathrm{t}=5 \mathrm{~min}$

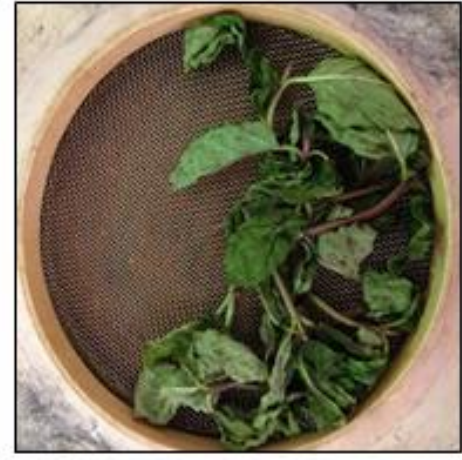

$\mathrm{t}=120 \mathrm{~min}$

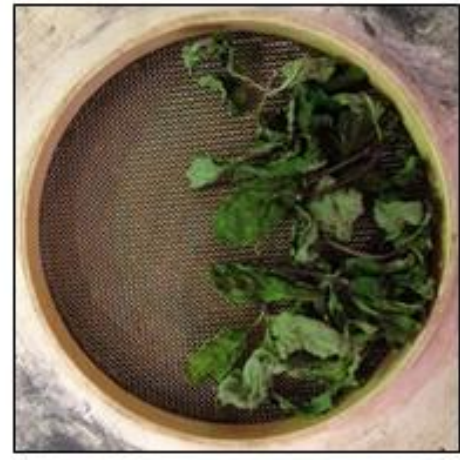

$\mathrm{t}=270 \mathrm{~min}$

Fonte: Acervo Pessoal, 2016

Devido à falta de homogeneidade dos leitos, optou-se por utilizar o ajuste à equação empírica de Lewis (Equação 2) ao invés da análise clássica baseada na solução da $2^{\mathrm{a}}$ Lei de Fick, que pressupõe a existência de meios homogêneos para o transporte de massa. Os valores de k ajustados são apresentados na Tabela 1.

Tabela 1- Valores de k ajustados para cada condição de secagem.

\begin{tabular}{ccccccc}
\hline & \multicolumn{7}{c}{ Parâmetro $\mathrm{k}\left(\mathrm{min}^{-1}\right)$} \\
\hline \multirow{2}{*}{ Temperatura $\left({ }^{\circ} \mathrm{C}\right)$} & \multicolumn{3}{c}{ Folha } & \multicolumn{2}{c}{ Haste } & \multicolumn{2}{c}{ Ramos } \\
\cline { 2 - 7 } & & \multicolumn{7}{c}{ Velocidade $(\mathrm{m} / \mathrm{s})$} \\
& 1,0 & 1,5 & 1,0 & 1,5 & 1,0 & 1,5 \\
\cline { 2 - 7 } 50 & 0,036 & 0,041 & 0,011 & 0,015 & 0,019 & 0,019 \\
60 & 0,060 & 0,089 & 0,020 & 0,028 & 0,024 & 0,035 \\
\hline
\end{tabular}

Fonte: Acervo pessoal, 2016.

Os valores de $\mathrm{k}$ obtidos corroboram a influência da temperatura na secagem da hortelã, pois para todas as condições há um aumento do parâmetro com o aumento da temperatura do ar de secagem. Nota-se que a influência é muito similar para folhas e hastes, em ambos os casos o parâmetro praticamente dobra de valor com o aumento de $10^{\circ} \mathrm{C}$ na temperatura. Para os ramos os parâmetros não chegam a dobrar de valor, mas sofrem um acréscimo considerável com o aumento da temperatura, por exemplo, à velocidade de $1,5 \mathrm{~m} / \mathrm{s}$ passam de $0,019 \mathrm{~min}^{-1}$ para $0,035 \mathrm{~min}^{-1}$. Na secagem condição de ramos a $50^{\circ} \mathrm{C}$ a constante de secagem se manteve igual a $0,019 \mathrm{~min}^{-1}$, nas demais condições o aumento da velocidade acarretou um pequeno aumento no valor de $\mathrm{k}$. Porém, essa influência não foi tão significativa quanto a influência da temperatura, a média dos acréscimos ficou em torno de $38 \%$. 


\section{CONCLUSÃO}

Por meio da análise dos dados obtidos foi observado concluir que a temperatura do ar tem maior influência na secagem convectiva das folhas e hastes de hortelã do que a velocidade do ar e que a secagem é controlada por mecanismos internos de transporte de umidade. Ao comparar a secagem dos diferentes materiais (hastes, folhas e ramos), mantendo as condições de secagem, notou-se que as folhas apresentam altas taxas de secagem quando comparadas com as hastes. Isso fez com que o tempo necessário para que o equilíbrio fosse atingido na secagem das hastes fosse muito maior do que na secagem das folhas. Assim, no caso da secagem de ramos pode-se produzir um material com umidade heterogênea. Os ramos apresentaram comportamento intermediário entre o de folhas e o de hastes. As constantes de secagem estimadas a partir dados experimentais variaram entre 0,036 e $0,089 \mathrm{~min}^{-1}$ para as folhas, entre 0,011 e 0,28 para as hastes e entre 0,019 e 0,035 para os ramos.

\section{REFERÊNCIAS}

CORRÊA, C.C.; ALVES, A.S. Plantas Medicinais como Alternativa de Negócios: caracterização e importância. In: Congresso da Sociedade Brasileira de Economia, Administração e Sociologia Rural, 2008, Rio Branco.

COSTA, A.B.S. Secagem Convectiva de Folhas de Hortelã: Análise Baseada no Ajuste de Correlações Empíricas, Superfícies de Respostas e Redes Neurais. Dissertação ( Mestrado em Engenharia Química), PPG-EQ, Universidade Federal de São Carlos, São Carlos, SP, 2013.

LIMA, R.A.B. Análise da secagem convectiva de folhas de manjericão (Ocimum basilicum L.). Tese (Doutorado em Engenharia Química), PPG-EQ, Universidade Federal de São Carlos, São Carlos, SP, 2013.

LIMA, R.A.B.; FERREIRA, M. C. Fluidized and vibrofluidized shallow beds of fresh leaves. Particuology, v. 9, p. 139-147, 2011.

PARK, K. J.; VOHNIKOVA, Z.; BROD, F. P. R. Evaluation of drying parameters and desorption isotherms of garden mint leaves (Mentha crispa L.). Journal of Food Engineering, v. 51, p. 193-199, 2002.

ROSANOVA, A.H.; FERREIRA, M.C. Secagem de Hortelã em Secador de Cesto Rotativo. In: Congresso Brasileiro de Engenharia Química, 19 a 22 de outubro de 2014, In: Anais do XX COBEQ, p. 1-10, 2014, Florianópolis, SC (CD-ROM).

ROSANOVA, A.H., MAIA, G.; FREIRE, F.B.; FERREIRA, M.C. A Neural based modeling approach for drying kinetics of mint branches and their fractions (leaves and stems). Advances in Chemical Engineering and Science, vol. 7, p. 154-174, 2017. 